\title{
Cyclooxygenase-2 overexpression is common in serrated and non-serrated colorectal adenoma, but uncommon in hyperplastic polyp and sessile serrated polyp/adenoma
}

\author{
Takako Kawasaki $^{\dagger 1}$, Katsuhiko Nosho ${ }^{\dagger 1}$, Mutsuko Ohnishi ${ }^{\dagger 1}$, \\ Yuko Suemoto1, Jonathan N Glickman², Andrew T Chan ${ }^{3,4}$, \\ Gregory J Kirkner ${ }^{4}$, Mari Mino-Kenudson ${ }^{5}$, Charles S Fuchs ${ }^{1,4}$ and \\ Shuji Ogino*1,2,6
}

\begin{abstract}
Address: ${ }^{1}$ Department of Medical Oncology, Dana-Farber Cancer Institute, Boston, MA, USA, ${ }^{2}$ Department of Pathology, Brigham and Women's Hospital, and Harvard Medical School, Boston, MA, USA, ${ }^{3}$ Gastrointestinal Unit, Massachusetts General Hospital, Boston, MA, USA, ${ }^{4}$ Channing Laboratory, Department of Medicine, Brigham and Women's Hospital, and Harvard Medical School, Boston, MA, USA, ${ }^{5}$ Department of Pathology, Massachusetts General Hospital, and Harvard Medical School, Boston, MA, USA and ${ }^{6}$ Department of Epidemiology, Harvard School of Public Health, Boston, MA, USA

Email: Takako Kawasaki - takako_kawasaki@dfci.harvard.edu; Katsuhiko Nosho - katsuhiko_nosho@dfci.harvard.edu;

Mutsuko Ohnishi - mutsuko_ohnishi@dfci.harvard.edu; Yuko Suemoto - yuyupon26@yahoo.co.jp;

Jonathan N Glickman - jglickman@partners.org; Andrew T Chan - achan@partners.org;

Gregory J Kirkner - gregory.kirkner@channing.harvard.edu; Mari Mino-Kenudson - mmino@partners.org;

Charles S Fuchs - chales_fuchs@dfci.harvard.edu; Shuji Ogino* - shuji_ogino@dfci.harvard.edu

* Corresponding author †Equal contributors
\end{abstract}

Published: 29 January 2008

BMC Cancer 2008, 8:33 doi:10.1/86/147|-2407-8-33

This article is available from: http://www.biomedcentral.com/I47I-2407/8/33

(c) 2008 Kawasaki et al; licensee BioMed Central Ltd.

This is an Open Access article distributed under the terms of the Creative Commons Attribution License (http://creativecommons.org/licenses/by/2.0), which permits unrestricted use, distribution, and reproduction in any medium, provided the original work is properly cited.
Received: 3 July 2007

Accepted: 29 January 2008

\begin{abstract}
Background: Cyclooxygenase-2 (COX-2, PTGS2) plays an important role in colorectal carcinogenesis. COX-2 overexpression in colorectal cancer is inversely associated with microsatellite instability (MSI) and the $\mathrm{CPG}$ island methylator phenotype (CIMP). Evidence suggests that MSI/CIMP+ colorectal cancer may arise through the serrated tumorigenic pathway through various forms of serrated neoplasias. Therefore, we hypothesized that COX-2 may play a less important role in the serrated pathway.
\end{abstract}

Methods: By immunohistochemistry, we assessed COX-2 expression in 24 hyperplastic polyps, 7 sessile serrated polyp/adenomas (SSA), 5 mixed polyps with SSA and adenoma, 27 traditional serrated adenomas, 515 non-serrated adenomas (tubular adenoma, tubulovillous adenoma and villous adenoma), 33 adenomas with intramucosal carcinomas, 96 adenocarcinomas with serration (corkscrew gland) and III adenocarcinomas without serration.

Results: Strong $(2+)$ COX-2 overexpression was more common in non-serrated adenomas $(28 \%$ $=143 / 515)$ than in hyperplastic polyps $(4.2 \%=1 / 24, p=0.008)$ and serrated polyps $(7$ SSAs and 5 mixed polyps) $(0 \%=0 / 12, p=0.04)$. Furthermore, any $(I+/ 2+)$ COX-2 overexpression was more frequent in non-serrated adenomas $(60 \%=307 / 515)$ than in hyperplastic polyps $(13 \%=3 / 24, \mathrm{p}<$ $0.000 \mathrm{I})$ and serrated polyps (SSAs and mixed polyps) $(25 \%=3 / \mathrm{I} 2, \mathrm{p}=0.03)$. Traditional serrated adenomas and non-serrated adenomas showed similar frequencies of COX-2 overexpression. Regardless of serration, COX-2 overexpression was frequent $(\sim 85 \%)$ in colorectal 
adenocarcinomas. Tumor location was not significantly correlated with COX-2 overexpression, although there was a trend towards higher frequencies of COX-2 overexpression in distal tumors (than proximal tumors) among hyperplastic polyps, SSAs, mixed polyps, traditional serrated adenomas and adenocarcinomas.

Conclusion: COX-2 overexpression is infrequent in hyperplastic polyp, SSA and mixed polyp with SSA and adenoma, compared to non-serrated and serrated adenoma. COX-2 overexpression becomes more frequent as tumors progress to higher grade neoplasias. Our observations suggest that COX-2 may play a less significant role in the serrated pathway of tumorigenesis; however, COX-2 may still play a role in later stage of the serrated pathway.

\section{Background}

Cyclooxygenase-2 (COX-2 or PTGS2, the HUGOapproved official gene symbol) has been considered to have an important role in the development of various cancers, including colorectal cancer [1-4]. COX-2 overexpression is observed in approximately $70-80 \%$ of colorectal cancer [5-7], and has been associated with poor prognosis in some but not all studies $[5,6]$. Regular use of COX inhibitor aspirin has been shown to decrease risks of colorectal cancer [8] and adenoma [9], and epidemiologic evidence supports that aspirin prevents colorectal cancer by inhibiting COX-2 [10]. In addition, COX-2 selective inhibitor celecoxib inhibits the growth of colorectal cancer cells in vitro $[11,12]$. Randomized trials have demonstrated that celecoxib decrease a risk of recurrent adenomas in high-risk individuals [13-15]. Thus, COX-2 is a promising chemopreventive target against colorectal neoplasia $[1,16,17]$. In light of these observations, it may be important to examine COX-2 expression levels in precursor lesions to predict effectiveness of chemoprevention by COX-2 inhibition $[10,18]$.

Serrated colorectal neoplasias comprise a family of lesions bearing some histological similarities, including an overall serrated configuration of neoplastic epithelial cells $[19,20]$. Serrated colorectal neoplasias include hyperplastic polyps, sessile serrated polyps/adenomas (SSAs), polyps with mixed features of SSA and adenoma, and traditional serrated adenomas. Accumulating evidence suggest that SSAs and polyps with mixed features of SSA and adenoma be precursor lesions for colorectal cancers, in particular, with BRAF mutation, high degree of MSI and widespread promoter methylation referred to as the $\mathrm{CpG}$ island methylator phenotype (CIMP) [19-23]. Thus, the term "the serrated pathway" has been used for multistep colorectal carcinogenesis through serrated precursor lesions [22-24].

COX-2 overexpression in colorectal cancer is inversely associated with MSI [25-27] and CIMP [27,28]. COX-2 has been shown to be frequently overexpressed in serrated adenomas [29,30], but infrequently in hyperplastic polyps [2,29-31]. COX-2 overexpression has been demon- strated in polyps in hereditary mixed polyposis syndrome [32] and familial juvenile polyposis [33], but not in fibroblastic polyps [34]. However, to our knowledge, no study has comprehensively examined COX-2 expression levels in various serrated and non-serrated colorectal neoplasias. Therefore, in this study, we have evaluated COX-2 expressions in various serrated and non-serrated colorectal neoplasias, including hyperplastic polyps, SSAs, traditional serrated adenomas, and adenocarcinomas with or without serration.

\section{Methods}

Study group

In order to recruit patients into this study, we utilized the databases of two large prospective cohort studies: the Nurses' Health Study ( $N=121,700$ women) [35], and the Health Professional Follow-up Study ( $N=51,500$ men) [36]. Informed consent was obtained from all participants prior to inclusion in the cohorts. A subset of the cohort participants developed colorectal polyps or colorectal cancers during prospective follow-up. Previous studies confirmed that our colorectal polyps/adenomas and colorectal cancers were representative as populationbased samples [8,10,35-37]. We requested paraffin embedded tissue samples of colorectal polyps that were endoscopically $1 \mathrm{~cm}$ or greater. Polyps endoscopically measuring less than $1 \mathrm{~cm}$ did not give reliable results for COX-2 expression because those small polyps became even much smaller after formalin fixation and careful histopathologic examination for diagnosis at multiple levels of sections (i.e., typically only approximately $1 \mathrm{~mm}$ of tissue was left). Tumors were selected based on availability of tumor tissue samples and assay results at the time of this study. As a result, a total of 611 colorectal polyp cases (290 from the men's cohort and 321 from the women's cohort) were included in this study (mean age 60.8 years old, median 62, standard deviation 8.2). For the purpose of comparison, 207 colorectal adenocarcinomas from the two cohorts were also evaluated for glandular serration and COX-2 expression. Tissue collection and analyses were approved by the Dana-Farber/Harvard Cancer Center and Brigham and Women's Hospital Institutional Review Boards. 


\section{Histopathologic evaluations}

Hematoxylin and eosin (HE) stained slides of the tumors were reviewed by a pathologist (S.O.), and colorectal neoplasias were classified according to the previously described criteria [19,38]: hyperplastic polyp, sessile serrated polyp/adenoma (SSA), polyp with mixed features of SSA and non-serrated adenoma (herein referred to as "mixed polyp"), traditional serrated adenoma (Figure 1), non-serrated adenomas (tubular adenoma, tubulovillous adenoma, and villous adenoma), and adenoma with focal intramucosal adenocarcinoma. All serrated polyps and adenomas were reviewed by a second pathologist (M.M.) and discrepant diagnoses were resolved by discussion. By definition, tubular adenoma contains villous architecture in $<25 \%$ of adenomatous epithelium. Tubulovillous adenoma and villous adenoma have between $25 \%$ and $75 \%$, and greater than $75 \%$ of villous epithelium, respectively. Serration in colorectal adenocarcinoma was evaluated according to the previously published criteria $[39,40]$. Similar to hyperplastic polyps, serrated colorectal polyps and traditional serrated adenomas, serrated adenocarcinomas were characterized by the presence of serrated epithelial cells projecting into the lumen of neoplastic glands (Figure 1). Glandular serration in colorectal cancer was evaluated by a pathologist (J.N.G.).

\section{Immunohistochemistry for COX-2}

Methods for COX-2 immunohistochemistry were previously described $[7,10]$. Briefly, antigen retrieval was per-

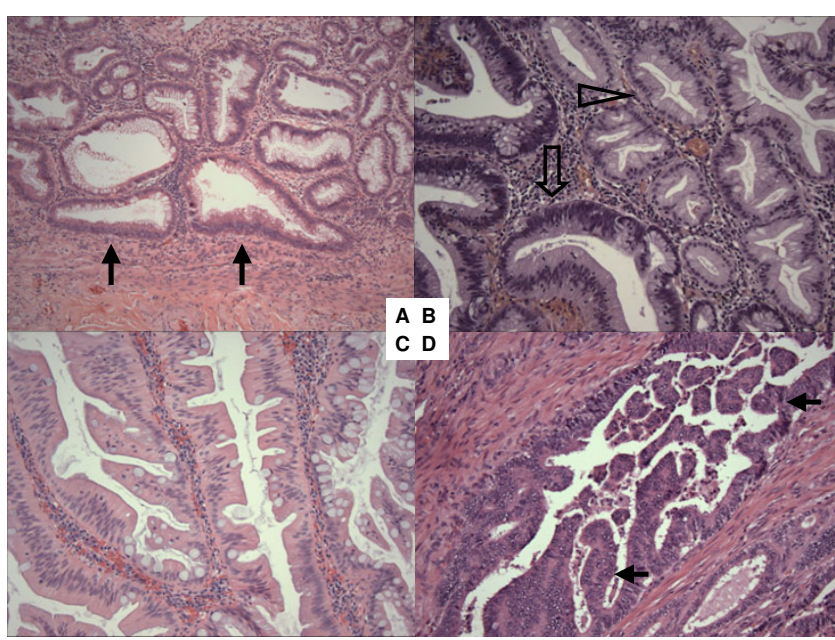

\section{Figure I}

Histopathology of serrated colorectal neoplasias. A. Sessile serrated polyp/adenoma (SSA) with abnormal crypt architecture (flat-based crypt) (arrow). B. Mixed polyp with SSA (empty arrowhead) and non-serrated adenoma (empty arrow). C. traditional serrated adenoma with abundant eosinophilic cytoplasm of epithelial cells. D. Colorectal adenocarcinoma with serration (arrows). formed by incubating deparaffinized tissue sections in citrate buffer (BioGenex, San Ramon, CA, USA) by a microwave for $15 \mathrm{~min}$. Tissue sections were incubated with $3 \% \mathrm{H}_{2} \mathrm{O}_{2}(20 \mathrm{~min}$ ), then with Avidin Block (Vector Laboratories, Burlingame, CA, USA) (15 min), and then with Biotin Block (Vector Laboratories) (15 min). Primary anti-COX-2 antibody (Cayman Chemical, Ann Arbor, MI, USA) (dilution 1:300) was applied overnight at $4^{\circ} \mathrm{C}$. Then, tissue sections were incubated with secondary antimouse antibody (Vector Laboratories) (20 min), and then with avidin-biotin complex conjugate (Vector Laboratories). Tissue sections were visualized by diamino benzidine (5 min) and methyl-green counterstain. Tissue microarrays (TMAs) were constructed as previously described [27], and used for immunohistochemistry in only colorectal cancer cases. For cases in which results from TMAs were equivocal, we stained whole tissue sections to obtain more definitive results. COX-2 expression in adenoma/polyp cells was interpreted as negative (no overexpression), weak overexpression $(1+)$, or strong overexpression (2+) (Figure 2). COX-2 expression in adenomas and polyps was often heterogeneous and we interpreted as overexpression even if staining of tumor cells was focal. Inflammatory cells served as an internal positive control. Appropriate positive control (colorectal cancer with known COX-2 overexpression) and negative control (colorectal cancer with known COX-2 overexpression treated by water instead of anti-COX-2 antibody)

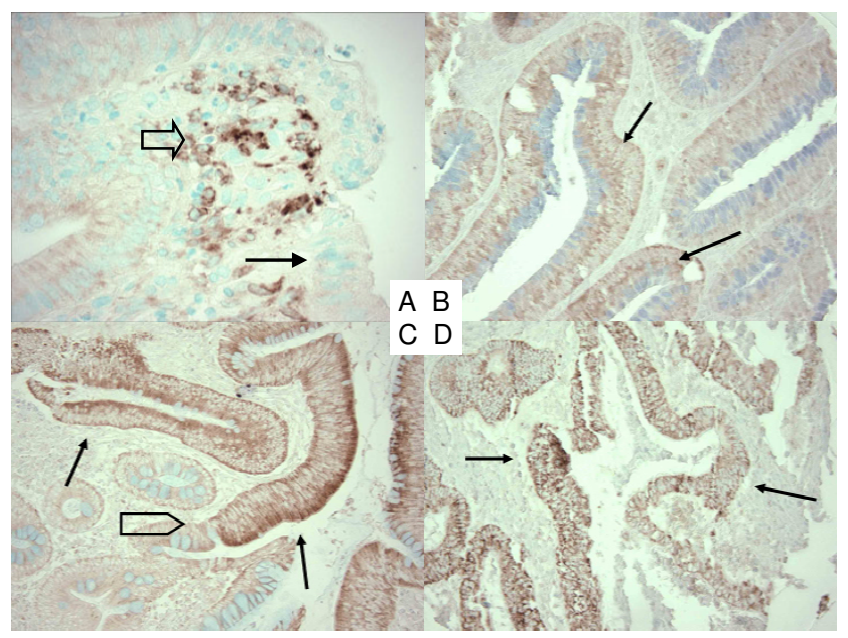

Figure 2

Immunohistochemistry for COX-2 in colorectal neoplasias. A. No overexpression in colorectal adenoma (arrow). Inflammatory cells serve as an internal positive control (empty arrow). B. Weak $(I+)$ overexpression in colorectal adenoma (arrows). C. Strong (2+) overexpression in colorectal adenoma (arrows). Note a junction between adenoma and normal appearing colon (empty block arrow). D. Strong $(2+)$ overexpression in colorectal adenocarcinoma (arrows). 
were included in each run of immunohistochemistry. COX-2 expression in colorectal cancer was interpreted as previously described [10]. All immunohistochemically stained slides were reviewed by a pathologist (S.O.) blinded from clinical or other laboratory data. A subset of cancer cases $(\mathrm{N}=108)$ was reviewed for COX-2 expression independently by two pathologists and the concordance rate was 92\% (kappa coefficient $=0.62, \mathrm{p}<0.001)[10]$.

\section{Statistical analysis}

Chi-square test (or Fisher's exact test when the number of cases in any category was less than 10) was performed for categorical data, and kappa coefficient to evaluate concordance of interpretation of COX-2 by the two observers was computed, using the SAS program (version 9.1, SAS Institute, Cary, NC). All p values were two-sided, and statistical significance was set as $\mathrm{p} \leq 0.05$.

\section{Results}

COX-2 overexpression is infrequent in hyperplastic polyp, sessile serrated polypladenoma (SSA) and mixed polyp with SSA and non-serrated adenoma

There were totals of 605 colorectal polyps and adenomas, including 24 hyperplastic polyps (HPs), 7 sessile serrated polyp/adenomas (SSAs), 5 mixed polyps (MPs) with SSA and non-serrated adenoma, 27 traditional serrated adenomas (SAs), 393 tubular adenomas, 109 tubulovillous adenomas, 13 villous adenomas, and 33 (non-serrated) adenomas with intramucosal adenocarcinoma. For the purpose of comparison, we also evaluated 207 colorectal adenocarcinomas; 96 with at least focal serration and 111 without serration. Among all 605 colorectal polyps and adenomas, weak $(1+)$ COX-2 overexpression was observed in 191 cases (32\%), and strong (2+) COX-2 overexpression was observed in 160 cases $(26 \%)$. There was no significant difference in the frequencies of COX-2 overexpression between tubular adenomas, tubulovillous adenomas and villous adenomas (Table 1). Therefore, we combined these adenomas into "non-serrated adenomas".

Compared to non-serrated adenomas, COX-2 expression levels were generally lower in hyperplastic polyps, sessile serrated adenomas (SSAs), and mixed polyps with SSA and adenoma. In contrast to non-serrated adenomas [showing $2+$ COX-2 in 28\% (143/515) of cases], strong $(2+)$ COX-2 expression was observed in none $(0 \%)$ of 12 serrated lesions including 7 SSAs and 5 mixed polyps ( $\mathrm{p}=$ $0.04)$ and in only $4.2 \%(1 / 24)$ of hyperplastic polyps ( $\mathrm{p}=$ $0.008)$ (Table 1 , Figure 3$)$. Any $(1+, 2+)$ COX-2 expression was more common in non-serrated adenomas $(60 \%=$ $307 / 515)$ than in hyperplastic polyps $(13 \%=3 / 24$, p < $0.0001)$, and serrated lesions including SSAs and mixed polyps $(25 \%=3 / 12, \mathrm{p}=0.03)$ (Table 1, Figure 4). Despite the presence of serrated appearance, traditional serrated adenomas showed the frequency of COX-2 overexpression similar to non-serrated adenomas. We noted that most hyperplastic polyps were small (typically $<3 \mathrm{~mm}$ on glass slides) although these were supposed to be endoscopically $\geq 1 \mathrm{~cm}$. Since we interpreted focal staining as positivity, the proportion of negative hyperplastic polyps might be merely function of size. Nonetheless, focal COX2 positivity was considered to be important, because focal positive cells might progress to COX-2 positive advanced lesions.

\section{COX-2 overexpression was not correlated with serration in colorectal adenocarcinoma}

In adenocarcinomas, regardless of the presence or absence of serration, COX-2 overexpression was frequent (Table 1). Strong (2+) COX-2 overexpression was more common in adenocarcinomas $(65 \%=135 / 207)$ than in non-serrated adenomas $(28 \%=143 / 515, \mathrm{p}<0.0001)$ (Figure 3$)$. Any $(1+$ or $2+)$ COX-2 overexpression was also more com-

Table I: Frequency of COX-2 overexpression in colorectal tumors

\begin{tabular}{|c|c|c|c|c|c|}
\hline Tumor type & Total & COX-2 negative & $\begin{array}{c}\text { COX-2 weak }(I+) \\
\text { overexpression }\end{array}$ & $\begin{array}{c}\text { COX-2 strong }(2+) \\
\text { overexpression }\end{array}$ & $\begin{array}{c}\text { COX-2 any }(1+, 2+) \\
\text { overexpression }\end{array}$ \\
\hline Hyperplastic polyp (HP) & 24 & $21(88 \%)$ & $2(8.3 \%)$ & I (4.2\%) & $3(13 \%)$ \\
\hline Sessile serrated polyp/adenoma (SSA) & 7 & $5(71 \%)$ & $2(29 \%)$ & 0 & $2(29 \%)$ \\
\hline Mixed polyp with SSA and adenoma (MP) & 5 & $4(80 \%)$ & I (20\%) & 0 & I (20\%) \\
\hline Total HP, SSA and MP & 36 & $30(83 \%)$ & $5(14 \%)$ & I $(2.8 \%)$ & $6(17 \%)$ \\
\hline Traditional serrated adenoma & 27 & $8(30 \%)$ & $14(52 \%)$ & $5(19 \%)$ & $19(70 \%)$ \\
\hline Tubular adenoma (TA) & 393 & $154(39 \%)$ & $132(34 \%)$ & $107(27 \%)$ & $239(61 \%)$ \\
\hline Tubulovillous adenoma (TVA) & 109 & $49(45 \%)$ & $27(25 \%)$ & $33(30 \%)$ & $60(55 \%)$ \\
\hline Villous adenoma (VA) & 13 & $5(38 \%)$ & $5(38 \%)$ & $3(23 \%)$ & $8(62 \%)$ \\
\hline Total non-serrated adenomas (TA, TVA, and VA) & 515 & $208(40 \%)$ & $164(32 \%)$ & $143(28 \%)$ & $307(60 \%)$ \\
\hline Adenoma with intramucosal carcinoma & 33 & $8(24 \%)$ & II (33\%) & $14(42 \%)$ & $25(76 \%)$ \\
\hline Adenocarcinoma with serration & 96 & $13(14 \%)$ & $18(19 \%)$ & $65(68 \%)$ & $83(86 \%)$ \\
\hline Adenocarcinoma without serration & III & $18(16 \%)$ & $23(21 \%)$ & $70(63 \%)$ & $93(84 \%)$ \\
\hline Total adenocarcinomas & 207 & $31(15 \%)$ & $41(20 \%)$ & $135(65 \%)$ & $176(85 \%)$ \\
\hline
\end{tabular}




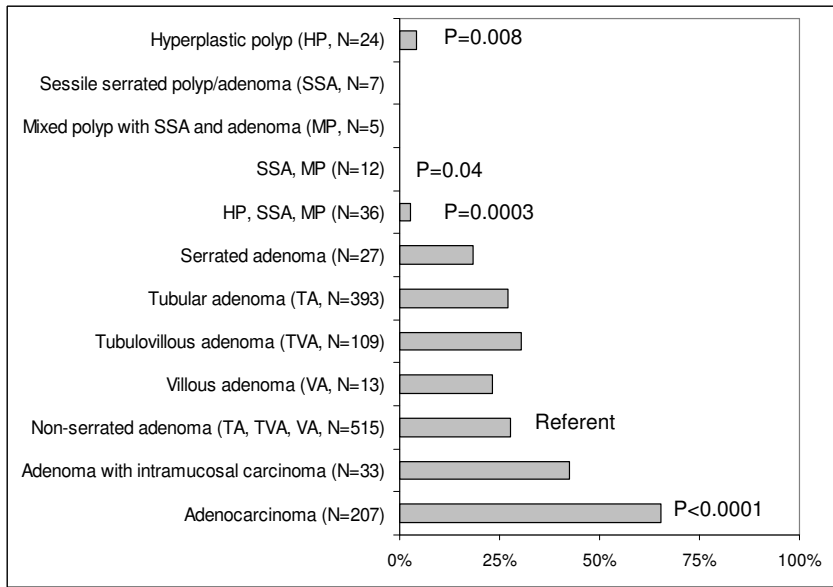

Figure 3

Frequency of strong (2+) COX-2 overexpression in various colorectal neoplasias.

mon in adenocarcinomas $(85 \%=176 / 207)$ than in nonserrated adenomas $(60 \%=307 / 515, \mathrm{p}<0.0001)$ (Figure $4)$. There was a trend that COX-2 overexpression was progressively more common from non-serrated adenomas, to adenomas with intramucosal carcinomas, and to adenocarcinomas.

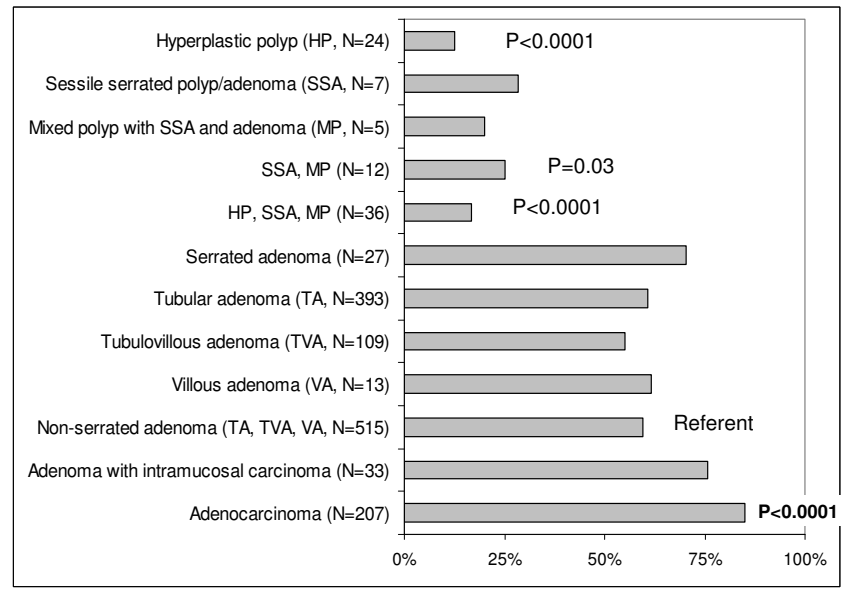

\section{Figure 4}

Frequency of any $(\mathrm{I}+$ or $2+) \mathrm{COX}-2$ overexpression in various colorectal neoplasias.

\section{overexpression in colorectal neoplasias}

We also examined the relationship between tumor location, histopathologic diagnosis and the frequency of COX-2 overexpression (Table 2). There were no significant differences in the frequencies of COX-2 overexpression between tumors in the proximal colon and those in the distal colorectum in any histopathologic category.

Table 2: Frequency of COX-2 overexpression in colorectal tumors according to tumor location

\begin{tabular}{|c|c|c|c|c|c|}
\hline Tumor type & Total & COX-2 negative & $\begin{array}{l}\text { COX-2 weak }(I+) \\
\text { overexpression }\end{array}$ & $\begin{array}{l}\text { COX-2 strong }(2+) \\
\text { overexpression }\end{array}$ & $\begin{array}{c}\text { COX-2 any }(\mathrm{I}+, 2+) \\
\text { overexpression }\end{array}$ \\
\hline \multicolumn{6}{|l|}{ Proximal* } \\
\hline Hyperplastic polyp (HP) & 5 & $5(100 \%)$ & 0 & 0 & 0 \\
\hline Sessile serrated polyp/adenoma (SSA) & 2 & $2(100 \%)$ & 0 & 0 & 0 \\
\hline Mixed polyp with SSA and adenoma (MP) & 1 & $\mathrm{I}(100 \%)$ & 0 & 0 & 0 \\
\hline Traditional serrated adenoma & 8 & $4(50 \%)$ & $3(38 \%)$ & I (I3\%) & $4(50 \%)$ \\
\hline Tubular adenoma (TA) & 120 & $53(44 \%)$ & 47 (39\%) & $20(17 \%)$ & $67(56 \%)$ \\
\hline Tubulovillous adenoma (TVA) & 32 & $11(34 \%)$ & $9(28 \%)$ & $12(38 \%)$ & $21(66 \%)$ \\
\hline Villous adenoma (VA) & 3 & I (33\%) & I (33\%) & I (33\%) & $2(67 \%)$ \\
\hline Adenoma with intramucosal carcinoma & 7 & $3(43 \%)$ & I (14\%) & $3(43 \%)$ & $4(57 \%)$ \\
\hline Adenocarcinoma with serration & 34 & $6(18 \%)$ & $7(21 \%)$ & $21(62 \%)$ & $28(82 \%)$ \\
\hline Adenocarcinoma without serration & 31 & $8(26 \%)$ & $7(23 \%)$ & $16(52 \%)$ & $23(74 \%)$ \\
\hline \multicolumn{6}{|l|}{ Distal* } \\
\hline Hyperplastic polyp (HP) & 17 & 14 (82\%) & $2(12 \%)$ & I (5.9\%) & $3(28 \%)$ \\
\hline Sessile serrated polyp/adenoma (SSA) & 4 & $2(50 \%)$ & $2(50 \%)$ & 0 & $2(50 \%)$ \\
\hline Mixed polyp with SSA and adenoma (MP) & 3 & $2(67 \%)$ & $1(33 \%)$ & 0 & I (33\%) \\
\hline Traditional serrated adenoma & 19 & $4(21 \%)$ & II (58\%) & $4(2 \mid \%)$ & $15(79 \%)$ \\
\hline Tubular adenoma $(\mathrm{TA})$ & 192 & $76(40 \%)$ & $57(30 \%)$ & $59(31 \%)$ & $116(60 \%)$ \\
\hline Tubulovillous adenoma (TVA) & 65 & $35(54 \%)$ & $16(25 \%)$ & $14(22 \%)$ & $30(46 \%)$ \\
\hline Villous adenoma (VA) & 9 & $4(44 \%)$ & $3(33 \%)$ & $2(22 \%)$ & $5(56 \%)$ \\
\hline Adenoma with intramucosal carcinoma & 12 & $2(17 \%)$ & $5(42 \%)$ & $5(42 \%)$ & $10(83 \%)$ \\
\hline Adenocarcinoma with serration & 34 & $3(8.8 \%)$ & $4(12 \%)$ & $27(79 \%)$ & 31 (9l\%) \\
\hline Adenocarcinoma without serration & 42 & $4(9.5 \%)$ & $9(21 \%)$ & $29(69 \%)$ & $38(90 \%)$ \\
\hline
\end{tabular}

\footnotetext{
* Proximal tumors were located from cecum to transverse colon, and distal tumors were located from splenic flexure to rectum.
} 
Nonetheless, there was a trend towards more frequent COX-2 overexpression in tumors in the distal colorectum than those in the proximal colon (among hyperplastic polyps, SSAs, mixed polyps, traditional serrated adenomas and adenocarcinomas).

COX-2 overexpression was not correlated with gender or age at diagnosis in any of the histopathologic categories examined (data not shown).

\section{Discussion}

We conducted this study to examine COX-2 expression in various serrated and non-serrated colorectal neoplasias. We have demonstrated that, compared to non-serrated adenomas, COX-2 overexpression is infrequent in hyperplastic polyps, sessile serrated polyps/adenomas (SSAs) and mixed polyps with SSA and adenoma. Traditional serrated adenoma and non-serrated adenoma show similar frequencies of COX-2 overexpression. In addition, COX-2 overexpression appears to become frequent as tumors progress to higher grade neoplasias, which is in agreement with a previous study showing a positive correlation between COX-2 expression and tumor grade in colorectal adenomas [41].

SSAs have been named in a variety of ways in the literature [19]. Torlakovic and Snover [42] found that the histopathologic features of polyps of "hyperplastic polyposis" were different from those of small sporadic hyperplastic polyps, and the term "sessile serrated adenoma" was coined to distinguish these distinct lesions from the more pedunculated lesions of traditional serrated adenomas [43]. Similar lesions have been reported under different names, including "serrated adenoma, superficial types" [44] and "serrated adenoma types 1 and 2" [45]. A recent review by Jass [23] used the term "sessile serrated polyp" because "this lesion lacks the traditional cytology of colorectal adenoma and in order to avoid confusion with serrated adenoma, it is referred to in this review as sessile serrated polyp". To reconcile this terminology issue, we used the term "sessile serrated polyp/adenoma (SSA)".

A few previous studies have examined COX-2 expressions in sporadic serrated adenomas as well as hyperplastic polyps. Arao et al. [30] examined COX-2 expression in serrated adenomas and hyperplastic polyps, and found that $71 \%$ of serrated adenomas showed moderate to intense positivity, in contrast to $32 \%$ of hyperplastic polyps showing weak to moderate positivity. Takeuchi et al. [29] examined COX-2 expression in serrated adenomas, tubular adenomas and hyperplastic polyps, but not in SSAs. They found that serrated adenomas of the cerebriform pattern showed a similar COX-2 expression score as tubular adenomas, and concluded that serrated adenoma of the cere- briform pattern should be treated similarly as tubular adenoma. There are other studies that have shown infrequent COX-2 overexpression in hyperplastic polyps $[2,31]$. However, to our knowledge, no study to date has compared COX-2 expression levels between SSAs, traditional serrated adenomas, non-serrated adenomas and adenocarcinomas.

The serrated pathway of colorectal carcinogenesis has been linked to widespread promoter methylation referred to as the CpG island methylator phenotype (CIMP) $[23,46]$. CIMP-high colorectal cancers are inversely correlated with COX-2 overexpression independent of MSI status [27]. Together with our current data on the inverse association between COX-2 and the serrated polyps, these observations support the proposed link between the serrated pathway and CIMP-high in colorectal cancer development.

Our data may have significant clinical implications because of emerging importance of COX-2 as a promising chemopreventive target $[10,18]$. Regular aspirin use has been shown to decrease risks of colorectal cancer as well as adenoma $[8,9]$. We have recently shown that regular aspirin use decreases a risk of COX-2-overexpressing colorectal cancer, but not a risk of COX-2-negative colorectal cancer [10]. In light of our findings, aspirin, celecoxib, and other non-steroidal anti-inflammatory drugs (NSAIDs) may be less frequently effective against serrated polyps than non-serrated adenomas. However, since COX-2 overexpression also appears to be dependent on tumor progression, it is possible that COX-2 inhibition may still be effective for the prevention of tumor progression in a subset of any types of precursor lesions.

\section{Conclusion}

In conclusion, hyperplastic polyp, sessile serrated polyp/ adenoma (SSA) and mixed polyp with SSA and adenoma infrequently overexpress COX-2, when compared to nonserrated adenomas and serrated adenomas. COX- 2 overexpression appears to be more frequent as tumors progress. Our observations suggest that COX-2 may play a less significant role in the serrated pathway of tumorigenesis, especially in early stage of polyp formation; however, COX-2 may still play a role in later stage of the serrated pathway.

\section{List of abbreviations}

COX-2: Cyclooxygenase-2 (PTGS2, the HUGO Gene Nomenclature Committee-approved official gene symbol); HP: Hyperplastic polyp; MP: Mixed polyp; SSA: Sessile serrated polyp/adenoma; TA: Tubular adenoma; TVA: Tubulovillous adenoma; VA: Villous adenoma. 


\section{Competing interests}

The author(s) declare that they have no competing interests.

\section{Authors' contributions}

$\mathrm{TK}, \mathrm{KN}$ and MO performed the assays, analyzed the data and drafted the manuscript. YS performed and interpreted the assays. JNG interpreted morphology of carcinomas and interpreted the data. ATC interpreted the data. GJK coordinated the study, and analyzed and interpreted the data. MM interpreted morphology of polyps/adenomas as a second pathologist, interpreted the data. CSF coordinated the study, discussed the study design and data. SO conceived the study, designed assays, analyzed and interpreted the data, and drafted the manuscript. All authors read and approved the final manuscript.

\section{Acknowledgements}

This work was supported by the United States (US) National Institute of Health (NIH)/National Cancer Institute (NCl) grants P0I CA87969, P0I CA55075, P50 CAI 27003 (to C.S.F.) and K07 CAI 22826 (to S.O.), and in part by the Bennett Family Fund for Targeted Therapies Research, and by the Entertainment Industry Foundation (EIF) through the EIF National Colorectal Cancer Research Alliance (NCCRA). M.O. was supported by a fellowship grant from the Japanese Foundation for Multidisciplinary Treatment of Cancer. We deeply thank the NHS and HPFS cohort participants who have generously agreed to provide us with biological specimens. We thank Walter Willett, Sue Hankinson, and many other staff members who implemented and have maintained the cohort studies. No conflict of interest is present. This study complied with the current laws of the United States.

\section{References}

I. Brown JR, DuBois RN: COX-2: a molecular target for colorectal cancer prevention. J Clin Oncol 2005, 23( I 2):2840-2855.

2. Sheehan KM, O'Connell F, O'Grady A, Conroy RM, Leader MB, Byrne MF, Murray FE, Kay EW: The relationship between cyclooxygenase- 2 expression and characteristics of malignant transformation in human colorectal adenomas. Eur J Gastroenterol Hepatol 2004, 16(6):619-625.

3. Larkins TL, Nowell M, Singh S, Sanford GL: Inhibition of cyclooxygenase-2 decreases breast cancer cell motility, invasion and matrix metalloproteinase expression. BMC Cancer 2006, 6: I8I.

4. Klenke FM, Gebhard MM, Ewerbeck V, Abdollahi A, Huber PE, Sckell A: The selective Cox-2 inhibitor Celecoxib suppresses angiogenesis and growth of secondary bone tumors: an intravital microscopy study in mice. BMC Cancer 2006, 6:9.

5. Fux R, Schwab M, Thon KP, Gleiter CH, Fritz P: Cyclooxygenase-2 expression in human colorectal cancer is unrelated to overall patient survival. Clin Cancer Res 2005, I I ( 13):4754-4760.

6. Soumaoro LT, Uetake H, Higuchi T, Takagi Y, Enomoto M, Sugihara $\mathrm{K}$ : Cyclooxygenase-2 expression: a significant prognostic indicator for patients with colorectal cancer. Clin Cancer Res 2004, I 0(24):8465-847I.

7. Ogino S, Brahmandam M, Cantor M, Namgyal C, Kawasaki T, Kirkner G, Meyerhardt JA, Loda M, Fuchs CS: Distinct molecular features of colorectal carcinoma with signet ring cell component and colorectal carcinoma with mucinous component. Mod Pathol 2006, I9(I):59-68.

8. Giovannucci E, Egan KM, Hunter DJ, Stampfer MJ, Colditz GA, Willett WC, Speizer FE: Aspirin and the risk of colorectal cancer in women [see comments]. N Engl J Med 1995, 333(1 0):609-6I4.

9. Giovannucci E, Rimm EB, Stampfer MJ, Colditz GA, Ascherio A, Willett WC: Aspirin use and the risk for colorectal cancer and adenoma in male health professionals [see comments]. Ann Intern Med I 994, I 2 I(4):24I-246.
10. Chan AT, Ogino S, Fuchs CS: Aspirin and the Risk of Colorectal Cancer in Relation to the Expression of COX-2. New Engl J Med 2007, 356(2I):2I3I-2I 42 .

II. Kazanov D, Dvory-Sobol H, Pick M, Liberman E, Strier L, ChoenNoyman E, Deutsch V, Kunik T, Arber N: Celecoxib but not rofecoxib inhibits the growth of transformed cells in vitro. Clin Cancer Res 2004, I O(I Pt I):267-27I.

12. Lev-Ari S, Strier L, Kazanov D, Madar-Shapiro L, Dvory-Sobol H, Pinchuk I, Marian B, Lichtenberg D, Arber N: Celecoxib and curcumin synergistically inhibit the growth of colorectal cancer cells. Clin Cancer Res 2005, I I (18):6738-6744.

13. Steinbach G, Lynch PM, Phillips RK, Wallace MH, Hawk E, Gordon GB, Wakabayashi N, Saunders B, Shen Y, Fujimura T, Su LK, Levin B: The effect of celecoxib, a cyclooxygenase-2 inhibitor, in familial adenomatous polyposis. N Engl J Med 2000, 342(26): 1946-1952.

14. Arber N, Eagle CJ, Spicak J, Racz I, Dite P, Hajer J, Zavoral M, Lechuga MJ, Gerletti P, Tang J, Rosenstein RB, Macdonald K, Bhadra P, Fowler R, Wittes J, Zauber AG, Solomon SD, Levin B: Celecoxib for the prevention of colorectal adenomatous polyps. N Engl J Med 2006, 355(9):885-895

15. Bertagnolli MM, Eagle CJ, Zauber AG, Redston M, Solomon SD, Kim K, Tang J, Rosenstein RB, Wittes J, Corle D, Hess TM, Woloj GM, Boisserie F, Anderson WF, Viner JL, Bagheri D, Burn J, Chung DC, Dewar T, Foley TR, Hoffman N, Macrae F, Pruitt RE, Saltzman JR, Salzberg B, Sylwestrowicz T, Gordon GB, Hawk ET: Celecoxib for the prevention of sporadic colorectal adenomas. N Engl J Med 2006, 355(9):873-884.

16. Dannenberg AJ, Lippman SM, Mann JR, Subbaramaiah K, DuBois RN: Cyclooxygenase-2 and epidermal growth factor receptor: pharmacologic targets for chemoprevention. J Clin Oncol 2005, 23(2):254-266.

17. Samoha S, Arber N: Cyclooxygenase-2 inhibition prevents colorectal cancer: from the bench to the bed side. Oncology 2005, 69 Suppl I:33-37.

18. Markowitz SD: Aspirin and colon cancer--targeting prevention? N Engl J Med 2007, 356(2 I):2195-2198.

19. Snover DC, Jass JR, Fenoglio-Preiser C, Batts KP: Serrated polyps of the large intestine: a morphologic and molecular review of an evolving concept. Am J Clin Pathol 2005, I 24(3):380-39I.

20. Torlakovic E, Snover DC: Sessile serrated adenoma: a brief history and current status. Crit Rev Oncog 2006, I 2(I-2):27-39.

21. Kambara T, Simms LA, Whitehall VLJ, Spring KJ, Wynter CVA, Walsh MD, Barker MA, Arnold S, McGivern A, Matsubara N, Tanaka N, Higuchi T, Young J, Jass JR, Leggett BA: BRAF mutation is associated with DNA methylation in serrated polyps and cancers of the colorectum. Gut 2004, 53(8): I |37-I | 44.

22. Jass JR: Serrated adenoma of the colorectum: a lesion with teeth. Am J Pathol 2003, 162(3):705-708.

23. Jass JR: Serrated adenoma of the colorectum and the DNAmethylator phenotype. Nat Clin Pract Oncol 2005, 2(8):398-405.

24. Jass JR: Serrated route to colorectal cancer: back street or super highway? J Pathol 200I, 193(3):283-285.

25. Sinicrope FA, Lemoine M, Xi L, Lynch PM, Cleary KR, Shen Y, Frazier ML: Reduced expression of cyclooxygenase 2 proteins in hereditary nonpolyposis colorectal cancers relative to sporadic cancers. Gastroenterology 1999, I I 7(2):350-358.

26. Karnes WE Jr., Shattuck-Brandt R, Burgart LJ, DuBois RN, Tester DJ, Cunningham JM, Kim CY, McDonnell SK, Schaid DJ, Thibodeau SN: Reduced COX-2 protein in colorectal cancer with defective mismatch repair. Cancer Res 1998, 58(23):5473-5477.

27. Ogino S, Brahmandam M, kawasaki T, Kirkner G], Loda M, Fuchs CS: Combined analysis of COX-2 and p53 expressions reveals synergistic inverse correlations with microsatellite instability and CpG island methylator phenotype in colorectal cancer. Neoplasia 2006, 8(6):458-464.

28. Toyota M, Shen L, Ohe-Toyota M, Hamilton SR, Sinicrope FA, Issa JP: Aberrant methylation of the Cyclooxygenase 2 CpG island in colorectal tumors. Cancer Res 2000, 60(15):4044-4048.

29. Takeuchi M, Kobayashi M, Ajioka Y, Honma T, Suzuki Y, Azumaya M, Narisawa R, Hayashi S, Asakura $\mathrm{H}$ : Comparison of cyclo-oxygenase $\mathbf{2}$ expression in colorectal serrated adenomas to expression in tubular adenomas and hyperplastic polyps. Int J Colorectal Dis 2002, I7(3): | 44-149.

30. Arao J, Sano Y, Fujii T, Kato S, Fu KI, Yoshino T, Ochiai A, Fujimori $\mathrm{T}$, Yoshida S: Cyclooxygenase-2 is overexpressed in serrated 
adenoma of the colorectum. Dis Colon Rectum 200I, 44(9): 1319-1323.

31. Maekawa M, Sugano K, Sano H, Miyazaki S, Ushiama M, Fujita S, Gotoda T, Yokota T, Ohkura H, Kakizoe T, Sekiya T: Increased expression of cyclooxygenase- 2 to $-I$ in human colorectal cancers and adenomas, but not in hyperplastic polyps. Jpn J Clin Oncol 1998, 28(7):42।-426.

32. Brazowski E, Misonzhnick-Bedny F, Rozen P: Cyclooxygenase-2 expression in the hereditary mixed polyposis syndrome. Dig Dis Sci 2004, 49(I I-I 2): 1906-19|I.

33. Brazowski E, Rozen P, Misonzhnick-Bedny F, Gitstein G: Characteristics of familial juvenile polyps expressing cyclooxygenase-2. Am J Gastroenterol 2005, I00(I): I30-138.

34. Groisman GM, Polak-Charcon S, Appelman HD: Fibroblastic polyp of the colon: clinicopathological analysis of 10 cases with emphasis on its common association with serrated crypts. Histopathology 2006, 48(4):43I-437.

35. Colditz GA, Hankinson SE: The Nurses' Health Study: lifestyle and health among women. Nat Rev Cancer 2005, 5(5):388-396.

36. Wei EK, Giovannucci E, Fuchs CS, Willett WC, Mantzoros CS: Low Plasma Adiponectin Levels and Risk of Colorectal Cancer in Men: A Prospective Study. J Natl Cancer Inst 2005, 97(22): $1688-1694$.

37. Giovannucci E, Colditz GA, Stampfer MJ, Willett WC: Physical activity, obesity, and risk of colorectal adenoma in women (United States). Cancer Causes Control 1996, 7:253-263.

38. Hamilton SR, Vogelstein B, Kudo S: Carcinoma of the colon and rectum. In Pathology and genetics of tumours of the digestive system World Health Organization classification of tumours Edited by: Aaltonen LA, Hamilton SR. Lyon, IARC Press; 2000.

39. Makinen MJ: Colorectal serrated adenocarcinoma. Histopathology 2007, 50(I): |3|-| 50.

40. Chirieac LR, Shen L, Catalano PJ, Issa JP, Hamilton SR: Phenotype of microsatellite-stable colorectal carcinomas with CpG island methylation. Am J Surg Pathol 2005, 29(4):429-436.

4I. Sato T, Yoshinaga K, Okabe S, Okawa T, Enomoto M, Takizawa T, Sugihara K: Cyclooxygenase-2 expression in colorectal adenomas. Dis Colon Rectum 2003, 46(6):786-792.

42. Torlakovic E, Snover DC: Serrated adenomatous polyposis in humans. Gastroenterology 1996, I I 0(3):748-755.

43. Torlakovic E, Skovlund E, Snover DC, Torlakovic G, Nesland JM: Morphologic reappraisal of serrated colorectal polyps. Am J Surg Pathol 2003, 27(I):65-8I.

44. Oka S, Tanaka S, Hiyama T, Ito M, Kitadai Y, Yoshihara M, Haruma K, Chayama K: Clinicopathologic and endoscopic features of colorectal serrated adenoma: differences between polypoid and superficial types. Gastrointest Endosc 2004, 59(2):213-219.

45. Mitomi H, Sada M, Kobayashi K, Igarashi M, Mori A, Kanazawa $H$, Nishiyama $Y$, Ihara $A$, Otani $Y$ : Different apoptotic activity and p2I(WAFI/CIPI), but not p27(KipI), expression in serrated adenomas as compared with traditional adenomas and hyperplastic polyps of the colorectum. J Cancer Res Clin Oncol 2003, I 29(8):449-455.

46. Minoo $P$, Jass J: Senescence and serration: a new twist to an old tale. J Pathol 2006, 210(2): I37-140.

\section{Pre-publication history}

The pre-publication history for this paper can be accessed here:

http://www.biomedcentral.com/1471-2407/8/33/prepub Publish with BioMed Central and every
scientist can read your work free of charge

"BioMed Central will be the most significant development for disseminating the results of biomedical research in our lifetime. "

Sir Paul Nurse, Cancer Research UK

Your research papers will be:

- available free of charge to the entire biomedical community

- peer reviewed and published immediately upon acceptance

- cited in PubMed and archived on PubMed Central

- yours - you keep the copyright

Submit your manuscript here:

http://www.biomedcentral.com/info/publishing_adv.asp
BioMedcentral 